\title{
Comparison of lipid extraction methods for the microalgae Acutodesmus obliquus
}

\author{
Diana Ximena Hurtado ${ }^{1}$, Claudia Lorena Garzón-Castro ${ }^{1,2}$, Jhon Cortés-Romero ${ }^{3}$, \\ Edisson Tello Camacho ${ }^{1,2^{*}}$
}

(1. Bioprospecting and CAPSAB Research Groups, Faculty of Engineering, Universidad de La Sabana, Cundinamarca 53753, Colombia; 2. Biosciences Doctoral Program, Faculty of Engineering, Universidad de La Sabana, Cundinamarca 53753, Colombia;

3. Department of Electrical and Electronic Engineering, Universidad Nacional de Colombia, Bogotá 53753, Colombia)

\begin{abstract}
Microalgae are widely used in the pharmaceutical and energy industries, therefore the conditions for their cultivation and extraction methods play an important role in the profiling and acquisition of lipids. The efficiency of lipid extraction from microalgae has attracted great interest from industry because of the wide variety of lipids and amounts that can be obtained. Acutodesmus obliquus (Scenedesmus obliquus UTEX 393) was used in this study. It was cultivated in Bold 3N medium modified with $75 \%$ nitrogen at $25^{\circ} \mathrm{C}, \mathrm{pH} 6.8,125 \mathrm{r} / \mathrm{min}$ and a photoperiod of $18 / 6 \mathrm{~h}$ and illuminated with white light provided by a Light-Emitting Diode Surface Mount Device extensions (LED SMD) with an intensity of $1200 \mu \mathrm{E} /\left(\mathrm{m}^{2} \cdot \mathrm{s}\right)$. The cells were stained with the Red Nile (RN) technique to indicate lipid production. Four extraction methods were compared, classical, microwave (MW), Soxhlet, and ultrasound (US), using the same solvent proportions (hexane: chloroform: methanol=1:2:3) All samples were analyzed with Fourier Transform Infrared Spectroscopy (FTIR) and Gas Chromatography coupled to Mass Spectrometry (GC-MS). The results showed: 1) lipid production detected by RN was consistent with microalgal growth; 2) the MW technique was the best extraction method, according to the statistical analysis through Randomized Complete Block (RCB) design and performance of 4.6\%; and 3) the presence of saturated and unsaturated acids was indicated by FTIR spectra. GC-MS was able to identify palmitic and linoleic acids as the likely major constituents of the sample.
\end{abstract}

Keywords: Acutodesmus obliquus, lipid extraction, trans-esterification, Red Nile (RN)

DOI: $10.25165 /$ j.ijabe.20181105.3748

Citation: Hurtado D X, Garzón-Castro C L, Cortés-Romero J, Tello E. Comparison of lipid extraction methods for the microalgae Acutodesmus obliquus. Int J Agric \& Biol Eng, 2018; 11(5): 211-217.

\section{Introduction}

Microalgae are unicellular organisms that assimilate $\mathrm{CO}_{2}$, nitrogen $(\mathrm{N})$ and phosphorus $(\mathrm{P})$ to form their biomass ${ }^{[1]}$. They contain significant amounts of micronutrients, such as proteins, carbohydrates and lipids, as well as pigments, polyphenols and minerals. These metabolites can be transformed into products of interest of the energy ${ }^{[2,3]}$, nutraceutical ${ }^{[4]}, \operatorname{cosmetic}^{[5]}$ and food industries ${ }^{[6]}$. Additionally, they are used in diverse applications related to environmental restoration ${ }^{[7,8]}$.

One of the principal difficulties in harvesting lipids from microalgae is the extraction procedure ${ }^{[9]}$. The establishment of an adequate extraction method for different applications is not an easy task because it requires chemical or physical techniques, thermal treatment and the use of special solvents ${ }^{[10]}$. A wide variety of extraction methods exist; the selection of one is based on efficiency,

Received date: 2017-08-25 Accepted date: 2018-08-01

Biographies: Diana Ximena Hurtado, Master candidate, Engineering, research interests: microalgae and bioprospecting, Email: dianahuva@unisaban.edu.co; Claudia Lorena Garzón-Castro, PhD, Assistant Professor, research interests: automation and control, and bio-systems applications, Email: claudia.garzon@ unisabana.edu.co; Jhon Cortés-Romero, PhD, Associate Professor, research interests: algebraic identification, active disturbance rejection control and robust control, Email: jacortesr@unal.edu.co.

*Corresponding author: Edisson Tello Camacho, PhD, Assistant Professor, research interest: bioprospecting, natural products, metabolomics, NMR and synthesis of natural products. Universidad de La Sabana, Chía, Colombia. Tel: +57-18615555 Ext: 25219, Email: edisson.tello@unisabana.edu.co. cost-efficiency, ease of application, precision and reproducibility ${ }^{[11]}$ Because of this, the scientific community is interested in the development of efficient and economical extraction techniques for lipids, mainly because of their great applicability in biofuel production $^{[9]}$.

The objective of this study was the establishment of the best method for extracting lipids from the microalgae A. obliquus due to its biomass potential for the biodiesel production, as well as, the higher potential to be used as lipid producer.

\section{Materials and methods}

\subsection{Microorganism and crop medium}

The green microalgae A. obliquus (Scenedesmus obliquus UTEX 393) was initially inoculated at $1.00 \times 10^{4}$ cells $/ \mathrm{mL}$ in a Modified Bold $3 \mathrm{~N}$ broth medium as suggested by UTEX. A modified Bristol's medium containing, in $\mathrm{g} / \mathrm{L}: \mathrm{NaNO}_{3}, 0.75$; $\mathrm{K}_{2} \mathrm{HPO}_{4}, \quad 0.075 ; \quad \mathrm{KH}_{2} \mathrm{PO}_{4}, \quad 0.175 ; \quad \mathrm{MgSO}_{4} \cdot 7 \mathrm{H}_{2} \mathrm{O}, \quad 0.075$; $\mathrm{CaCl}_{2} \cdot 2 \mathrm{H}_{2} \mathrm{O}, 0.025 ; \mathrm{NaCl}, 0.025$; and the following additives, in $\mathrm{mL} / \mathrm{L}$ : PI-V metal solution, 6; soil water GR+medium, 40; vitamin B12, 1; biotin vitamin, 1; thiamine vitamin, 1 was also used. Cultures of microalgae were grown with oxygen-free $\mathrm{CO}_{2}$.

\subsection{Experimental procedure}

The laboratory at Universidad de La Sabana has a prototype system that was designed and implemented using a PLC S7 1200 Siemens (Republic of Austria). It allows control of temperature, light/dark cycle, and $\mathrm{pH}$ monitoring. Figure 1 illustrates the connections between the components of the system: a) PLC, b) Boards, c) sensors and actuators, d) Human-Machine Interface 
(HMI) and e) production system.

a) PLC. The PLC is responsible for process control, which involves operations such as sensor data acquisition, control algorithm execution and driving the actuators according to the control signal generated. Furthermore, the PLC constantly communicates with the HMI.

b) Boards. The prototype contains the following boards: 1) analogue input, 2) digital input, 3) thermocouple management, 4) digital output and 5) analogue output. These boards detect signals from the sensors and determine which actions each actuator must execute.

c) Sensors and actuators. The sensors were a type $\mathbf{J}$ thermocouple and $\mathrm{pH}$ electrodes (Sensorex). The actuators comprise heaters, cooling fans, electromagnetic plates for agitation (Velp Scientifica) and Light-Emitting Diode Surface Mount Device extensions (LED SMD).

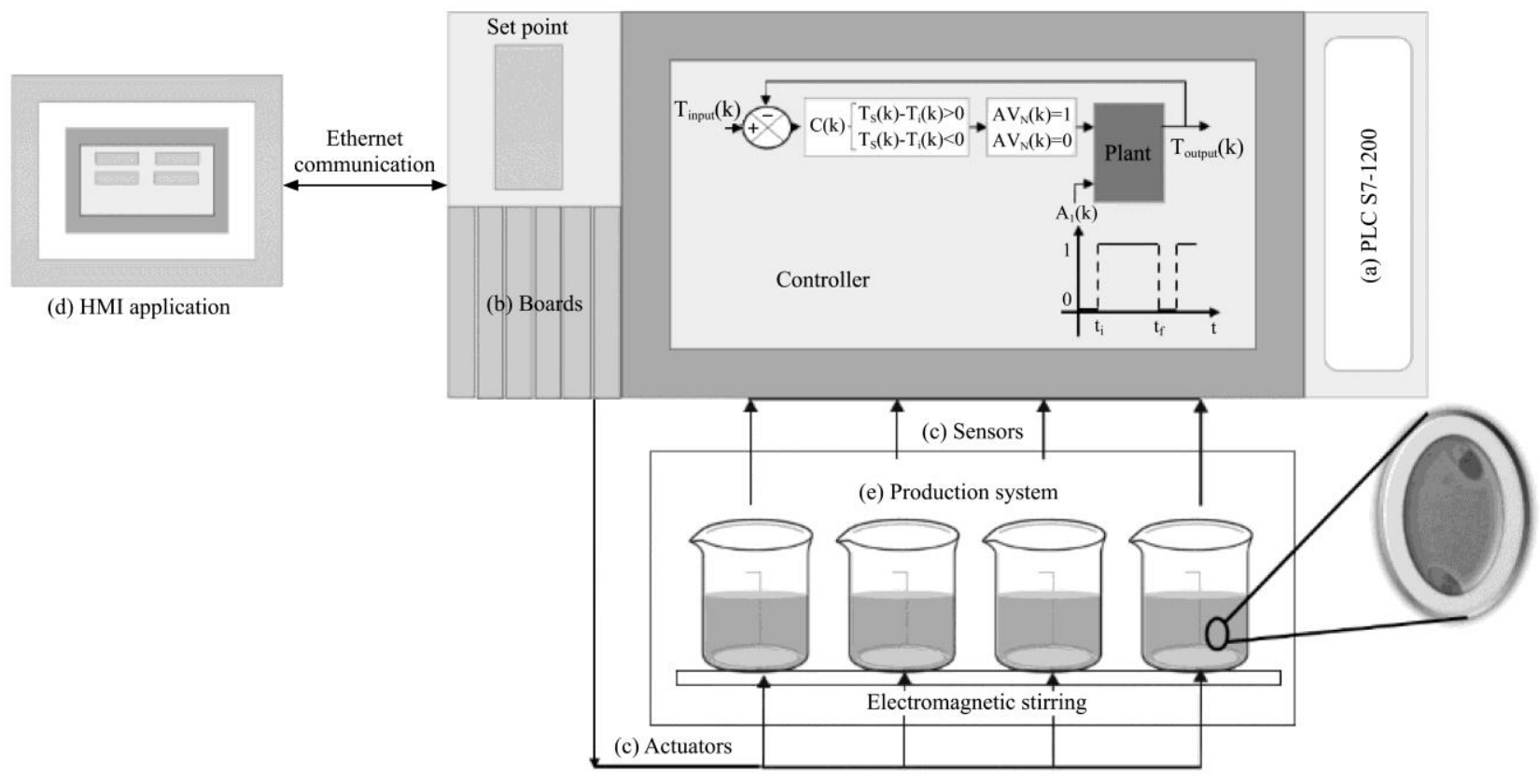

a. Programmable Logic Controller (PLC) b. Boards c. Sensors and actuators d. Human-Machine Interface e. Production system

Figure 1 Connections between the components of the system

\subsection{Experimental conditions}

The microscope used for photography was a Nikon Eclipse 80i, with a DS-Fil camera and a DS-U2 controller. The settings in each experiment were: stirring speed $125 \mathrm{r} / \mathrm{min}$, time $15 \mathrm{~d}, \mathrm{pH} 6.8$, temperature $25^{\circ} \mathrm{C}$, light/dark cycle $18 / 6 \mathrm{~h}$, white illumination with a SMD LED of $1200 \mu \mathrm{E} /\left(\mathrm{m}^{2} \cdot \mathrm{s}\right) \quad(\mathrm{QSL}-2100$, Biospherical Instruments Inc.) and working volume $2.7 \mathrm{~L}$.

\subsection{Experimental stages}

The study was performed in three stages: the first was batch cultivation of microalgae in a closed photobioreactor (PBR) with a controlled temperature, $\mathrm{pH}$, photoperiod and irradiance. The presence of lipids was periodically determined using the Red Nile (RN) technique. In the second stage, the different extraction methods were evaluated using the same solvent mixture for all evaluations. In the last stage, the lipids were trans-esterified to obtain methyl esters, which were analyzed via FTIR and GC-MS to identify the fatty acid profile produced by each extraction method. Four techniques were compared: classical, MW, Soxhlet, and US with solvents.

\subsection{Analytical determinations}

\subsubsection{Cell growth}

Each experiment was tracked every $36 \mathrm{~h}$ by sampling $500 \mu \mathrm{L}$ d) HMI. This application accesses the data blocks in the PLC memory for storage and display. It enables the user to interact with the control process. The user configures the experimental conditions, such as 1) the temperature set-point, 2) duration of the light/dark cycle, 3) wave longitude for crop illumination and whether it is required and 4) $\mathrm{pH}$ monitoring. Additionally, the HMI can follow the process, checking that the work stands correspond with the configurations set at the beginning of the experiment.

e) Production system. The production system comprises four PBRs. Each PBR is characterized by: 1) a 3 L beaker; 2) an acrylic cap with holes to allow gas exchange, sample acquisition, supply $\mathrm{CO}_{2}$ and air, introduce temperature and $\mathrm{pH}$ sensors, and central illumination; 3) external and central illumination, which was provided by the LED SMD extension; and 4) electromagnetic agitator. 
freeze-drying, followed by extraction with a solvent mixture of hexane: chloroform: methanol in a 1:2:3 proportion. In each extraction, $12 \mathrm{~mL}$ of solvent was applied to $2.0 \mathrm{~g}$ of freeze-dried biomass.

\subsubsection{Classical extraction}

Two gram of biomass was extracted twice with $12 \mathrm{~mL}$ of solvent for $12 \mathrm{~h}$ for each extraction. Then the organic phase was filtered and subjected to rotary evaporation under a vacuum and until the moment the trans-esterification procedure was carried out. 2.6.2 Microwave extraction

Microwave extraction (1.4 kW, $2.45 \mathrm{GHz}, \mathrm{LG}, \mathrm{MH} 1443 \mathrm{XAR}$, South Korea) was performed with $2.0 \mathrm{~g}$ of biomass and $12 \mathrm{~mL}$ of solvent using 4 pulses of $15 \mathrm{~s}$ each with $90 \mathrm{~s}$ of rest time between pulses and the microwave was set to a $50 \%$ power level.

\subsubsection{Soxhlet extraction}

Soxhlet extraction was performed in a $25-\mathrm{mL}$ vessel, using $2.0 \mathrm{~g}$ of biomass and $12 \mathrm{~mL}$ of solvent for eight hours at $65^{\circ} \mathrm{C}$ using a cellulose dash that was $5 \mathrm{~cm}$ long by $2 \mathrm{~cm}$ wide

\subsubsection{Ultrasound extraction}

Ultrasound extraction was performed in an ELMA, Trasonic TI-H 10 (750 W, Germany), using $2.0 \mathrm{~g}$ of biomass and $12 \mathrm{~mL}$ of solvent and a frequency of $45 \mathrm{kHz}$ for $15 \mathrm{~min}$, the equipment was set to a $100 \%$ power level and $20^{\circ} \mathrm{C}$. Each sample was extracted twice, with a rest time of $5 \mathrm{~min}$.

\subsection{Lipid identification}

The crude extracts obtained were individually trans-esterified using $3.5 \mathrm{~mL}$ of $\mathrm{BF}_{3} \cdot \mathrm{MeOH}(14 \%), 85^{\circ} \mathrm{C}$, for $50 \mathrm{~min}$ in an oil bath. Then, the samples were brought to room temperature and $3 \mathrm{~mL}$ of hexane was added; two phases were then separated. The organic phase was concentrated under a vacuum to obtain methyl esters, which were stored in vials for subsequent analysis.

Methyl esters were analyzed by FTIR (Termo Scientific $\AA$, Nicolet iS10). The composition of the FAMEs was further analyzed with an Agilent 7890B GC (Agilent Technologies Inc., USA) coupled to an Agilent 5977A Mass Selective Detector, an HP-5 MS column $(50 \mathrm{~m}$ length $\times 0.25 \mathrm{~mm}$ i.d. $\times 0.25 \mu \mathrm{m}$, stationary phase) with a split injection of 10:1 and an injection volume of $1 \mu \mathrm{L}$. The FAMEs Mix C8-C24 was used as an external standard. The samples were dissolved in hexane. The carrier gas was helium at a flow rate $0.6 \mathrm{~mL} / \mathrm{min}$. The column oven temperature program began at $60^{\circ} \mathrm{C}$ and was increased to $200^{\circ} \mathrm{C}$ at $10^{\circ} \mathrm{C} / \mathrm{min}$. After $200^{\circ} \mathrm{C}$, the ramp changed to $5^{\circ} \mathrm{C} / \mathrm{min}$ until $250^{\circ} \mathrm{C}$ was reached. The ramp was changed back to $10^{\circ} \mathrm{C} / \mathrm{min}$ from $250^{\circ} \mathrm{C}$ to $300^{\circ} \mathrm{C}$. The total program time was $30.5 \mathrm{~min}$.

\subsection{Statistical analysis}

All extractions were realized in quadruplicated to confirm their reproducibility though RCB design, for comparing four treatments in four blocks, with each treatment appearing exactly once in every block. A Statistical Analysis Software (SAS) used to the validation of the normality for Shapiro-Wilk test and analyze the difference between the weigh and percentage of lipids for each treatment.

\section{Results and discussion}

\subsection{Optimization of experimental conditions}

The optimal medium to grow A. obliquus microalgae was chosen from two different media recommended in $\mathrm{UTEX}^{[14]}$ for the growth of this species. The results showed that best medium was Modified Bold 3N, according to the biomass productivity.

The temperature was maintained at $25^{\circ} \mathrm{C}$ because a study by $\mathrm{Li}$ et al. ${ }^{[15]}$, indicated that the production of biomass in the microalgal culture was significantly higher at $20^{\circ} \mathrm{C}, 25^{\circ} \mathrm{C}$ and $30^{\circ} \mathrm{C}(313.3 \pm$ $6.7 \mathrm{~g} ; 340.0 \pm 13.3 \mathrm{~g} ; 340.0 \pm 6.7 \mathrm{~g})$ than at $10^{\circ} \mathrm{C}(200.0 \pm 6.7 \mathrm{~g})$. The $\mathrm{pH}$ of the medium was maintained at 6.8 , as recommended by the UTEX Culture Collection of Algae ${ }^{[16]}$; however, Hodaifa et al. ${ }^{[17]}$ showed that $\mathrm{pH}$ variations change the lipid profile. For example, linoleic acid was higher at $\mathrm{pH} 8.0$, but considerably lower at $\mathrm{pH}$ 9.0. It has also been shown that monounsaturated fatty acids were present in a greater amount at $\mathrm{pH}$ 6.0, while a greater amount of the saturated acids was observed at $\mathrm{pH}$ 7.0. An irradiance of $1200 \mu \mathrm{E} /\left(\mathrm{m}^{2} \cdot \mathrm{s}\right)$ was used because it was the maximum for the white SMD LED.

Another condition considered was the percentage of $\mathrm{N}$ in the medium, Shen et al. ${ }^{[18]}$ concluded that a reduction in $\mathrm{N}$ did not cause a notable decrease in the microalgal growth rate. However, a lack of $\mathrm{N}$ increased the amount of lipids produced compared to lipid production in $\mathrm{N}$-saturated medium. Therefore, in presented work $500 \mu \mathrm{L}$ samples of microalgae were taken every $36 \mathrm{~h}$ to monitor growth, as indicated by the living cells produced by $A$. obliquus over $15 \mathrm{~d}$ (Figure 2). The results showed that the production rate of living cells was higher at $75 \% \mathrm{~N}$ than at $100 \% \mathrm{~N}$; however, at the end of the experiment, the number of living cells was similar for both $\mathrm{N}$ levels. This result is noteworthy because the percentage of $\mathrm{N}$ used allows larger quantities of biomass to be produced in less time.

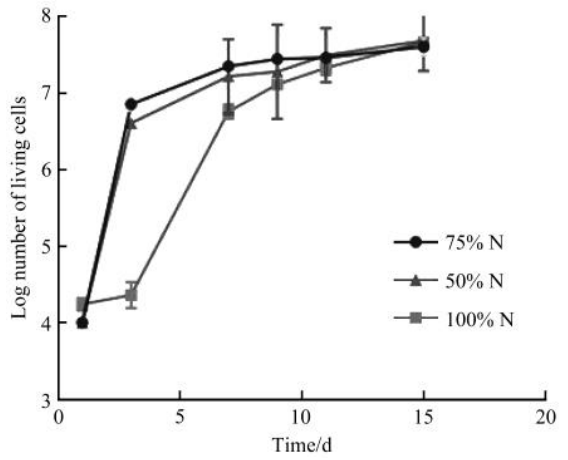

Figure 2 Number of living cells produced during the $15 \mathrm{~d}$ experiment with different nitrogen concentrations

\subsection{Lipid vacuoles determination}

The NR fluorophore (9-diethylamino-5H-benzo[ $\alpha]$ phenoxazine-5-one) is a hydrophobic and metachromatic coloring agent that allows the detection and quantification of the microalgal neutral lipid content ${ }^{[17-20]}$. Lipid accumulation in the microalgae was periodically established by using this technique. The lipid vacuoles had a fluorescent yellow color, while chlorophyll was stained red. The results showed that the cell size and lipid production became saturated after $15 \mathrm{~d}$, so the experiment was terminated at this time (Figure 3 ).

In Figure 3, the changes in the lipids in the microalgae at different cultivation times are shown. The greatest increase occurred between the 7th and 11th days. Fewer yellow dots were evident on the first day (Figure 3a), while at the 7th day (Figure 3c), the yellow lipid vacuoles were grouped and easily observed. Between the 11th and 15th days (Figures $3 \mathrm{e}$ and $3 \mathrm{f}$ ), the vacuoles showed the greatest lipid production and an intense yellow color and greater cell size was evident. These results indicate that high cell growth does not necessarily imply high lipid production because, as Figure 3 shows, at day 9 with $75 \%$ N, the culture had nearly reached stationary phase, but maximum lipid production began on day 11 . 


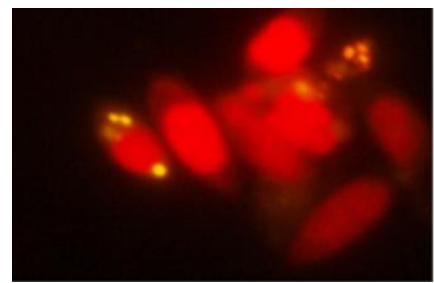

a. Inoculum (1st day)

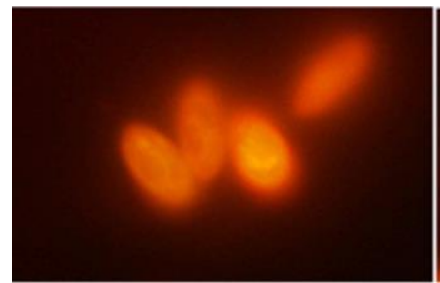

c. Time 2 (7th day of cultivation)

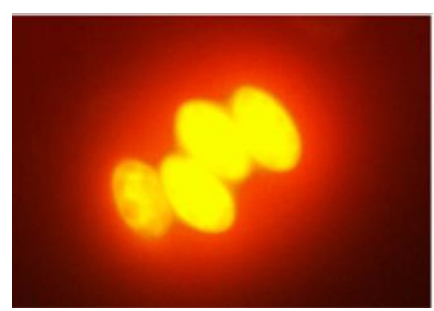

e. Time 4 (11th day of cultivation) Note: The yellow dots are lipids.

Figure 3 A. obliquus cell stained with Nile Red

The protein percentage produced during 15 days of experimentation is shown in Figure 4. As expected, the protein content increased with increased cell growth. Additionally, a marked similarity with lipid vacuole production during the experiment exists, which could be related to the biosynthetic process in A. obliquus that produces lipids as a result of catabolism. At the end of the experiment, a decreasing production of protein was observed, which could be associated with the energy requirements of the cells.

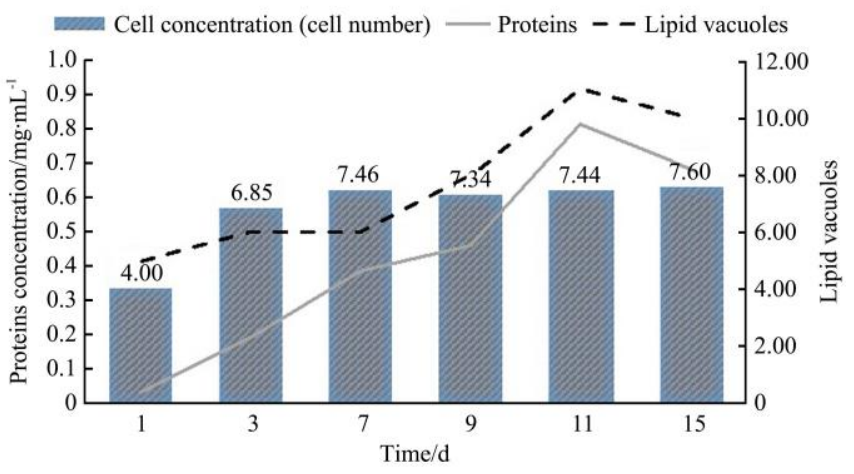

Figure 4 Cell concentration and protein concentration

\subsection{Extraction methods comparison}

At the end of the experiment, the biomass was decanted and removed from the medium, centrifuged, frozen and lyophilized. Forty grams of dry biomass was obtained from this PBR experiment. The biomass was split into homogeneous quantities of $2 \mathrm{~g}$, which were used in the four extraction methods (classical, MW, Soxhlet and US). Table 1 shows the results for each method.

The crude extract is the product obtained after rotary evaporation, which contains other metabolites that may be extractable with the solvents employed. Table 1 indicates that the classical extraction was the best method, and Soxhlet produced the least amount of crude extract, while the MW and US extractions produced similar amounts. Although classical extraction produced the greatest amount of crude extract, this result does not imply that it is the best lipid extraction method because in addition to lipids, the crude extract may contain terpenes, proteins, phenolics compounds, among other substances.

Table 1 Biomass and lipids extracted from different types of extractions

\begin{tabular}{lcccc}
\hline \multirow{2}{*}{ Product } & \multicolumn{4}{c}{ Extraction methods } \\
\cline { 2 - 5 } & Classical & Microwave & Ultrasonic & Soxhlet \\
\hline Crude extract/mg $\cdot \mathrm{L}^{-1}$ & 281.81 & 113.46 & 112.09 & 50.51 \\
Average lipid content/mg $\cdot \mathrm{L}^{-1}$ & 581.73 & 610.26 & 605.23 & 621.55 \\
Lipid productivity/mg $(\mathrm{L} \cdot \mathrm{d})^{-1}$ & 38.78 & 40.68 & 40.35 & 41.44 \\
\hline
\end{tabular}

Data were evaluated under a RCB design ${ }^{[23]}$. The Shapiro-Wilk test for normality has a $p$-value of 0.9767 , which reflects the normal nature of the residuals and the analysis of variance showed a significant effect at 0.0495 for the treatments. The best extraction method was determined according to the amount of lipids obtained. The comparison of means between treatments showed that the extractions with wave treatment (MW and US) are better than the classic treatments (Classical and Soxhlet), with a probability of 0.0113 , while the others comparisons presented in Table 2 do not has significant differences. As Table 1 and Figure 5 indicate, all of the methods produced approximately the same amount of lipids, but the best method in this study was extraction by MW. Although Soxhlet produced a greater amount, it was not significantly different from MW. However, the Soxhlet method takes eight hours to produce a product, but MW requires 4 pulses of $15 \mathrm{~s}$ with $90 \mathrm{~s}$ of rest time. This result is in agreement with a report by Balasubramanian et al. ${ }^{[24]}$ Similarly, classical extraction takes $48 \mathrm{~h}$ and requires twice the amount of solvent.

Table 2 Statistical probability for comparisons of treatments

\begin{tabular}{lcl}
\hline \multicolumn{1}{c}{ Parameter } & $t$ value & $\operatorname{Pr}>|t|$ \\
\hline Waves $v s$ Classic & -3.17 & 0.0113 \\
MW vs US & 0.17 & 0.8722 \\
Soxhlet $v s$ Classic & 1.24 & 0.2460 \\
MW vs others & -1.97 & 0.0807 \\
US vs others & -1.70 & 0.1240 \\
\hline
\end{tabular}

Note: $t=$ Student's $t$-distribution, $\operatorname{Pr}=$ Probability.

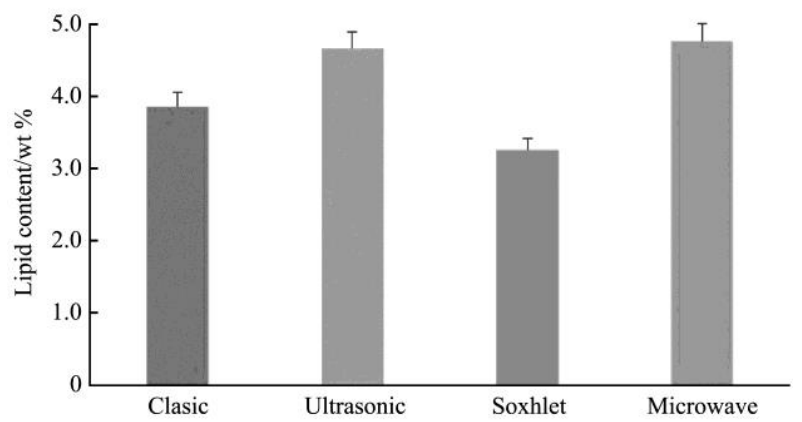

Figure 5 Lipid extraction efficiency according to method

According to Figure 6, the samples treated by classical extraction were not differentiated from the others extraction; therefore, these belong to both groups A and B. This means that the statistics of MW and US treatments are equal, classical is intermediate and Soxhlet is the treatment with lower yield. The US and MW extractions yield a similar amount of lipids (4.6\%), but US takes approximately $35 \mathrm{~min}$ and MW requires only $60 \mathrm{~s}$ of 
irradiation. Furthermore, less time ( $1 \mathrm{~min}$ for MW) versus $35 \mathrm{~min}$ (US), $8 \mathrm{~h}$ (Soxhlet), and $24 \mathrm{~h}$ (classical) was required to yield a similar lipid recovery, demonstrating the advantages of MW compared with the other lipid extraction methods. These results are in accord with other results reported in the literature. For example, Balasubramanian et al. ${ }^{[24]}$ found that extraction by MW drastically reduced the process time by approximately 10 times for a species of A. obliquus microalgae compared with Soxhlet extraction and a warm bath. Florentino de Souza Silva et al. ${ }^{[25]}$ obtained the best results in terms of the lipid yield using MW $(33.7 \% \pm 5.3 \%)$, followed by Electroflocculation with an alternating current $(24.8 \% \pm 7.1 \%)$, autoclave $(15.4 \% \pm 2.3 \%)$, and US $(13.3 \% \pm 3.0 \%)$. Prabakaran and Ravindran ${ }^{[26]}$ found that US and MW extraction were more efficient for Chlorella sp. and Nostoc sp.

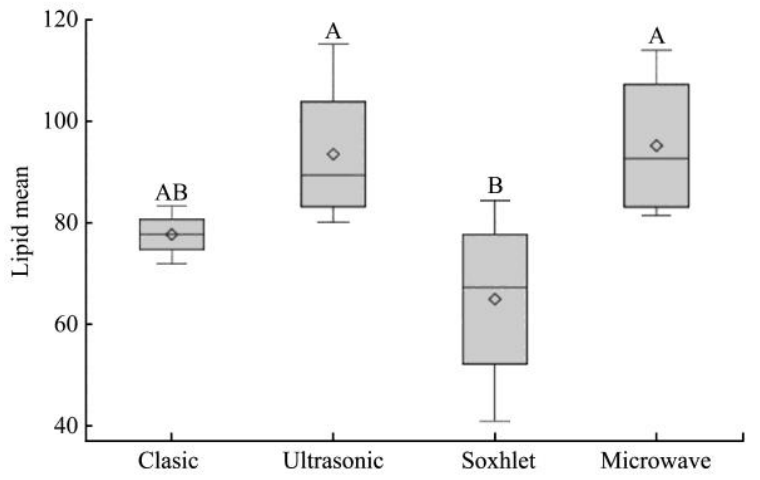

Note: Means with the same letter are not significantly different.

Figure 6 Box and whiskers diagram for the means of lipid weight of each treatments.

\subsection{Lipid characterization}

It was frequently reported in literature that the extraction time affects the fatty acid profile; e.g., Balasubramanian et al. ${ }^{[24]}$ found that the oil obtained from a Soxhlet extraction contained a large percentage of saturated fatty acids (86\%) and a very low percentage of unsaturated fatty acids (14\%). They noticed that the oil extracted when microwaves were used as a heat source resulted in a high percentage of $\omega-3$ and $\omega-6$ fatty acids compared to other methods. Koberg et al. ${ }^{[27]}$ compared the efficiency of the MW versus the US extraction of lipids from the algae Nannochloropsis and found that palmitic (C16:0) and palmitoleic (C16:1) acids were present in the highest proportion using MW and US extraction, indicating that a high concentration of saturated fatty acids was obtained. Prabakaran and Ravindran ${ }^{[26]}$ used different extraction methods (autoclave, bead beating, WW, US, and treatment with $\mathrm{NaCl}$ solution to 10\%) in Chlorella sp., Nostoc sp. and Tolyphothrix sp. and found a large amount of oleic acid from Nostoc sp. and Tolypothrix sp., while linoleic acid predominated with Chlorella sp.

The previous discussion emphasizes the need for a comprehensive investigation of the lipids produced by A. obliquus. The lipids obtained via the four methods (classical, MW, Soxhlet, and US) were compared with FTIR spectroscopy and GC-MS. FTIR analyses were used to establish chemical and structural differences between the lipids. The spectra for the four extractions are shown in Figure 7. The broad band between $2900 \mathrm{~cm}^{-1}$ and $3600 \mathrm{~cm}^{-1}$ represents the stretch of the $\mathrm{O}-\mathrm{H}$ bond, the band at $1045 \mathrm{~cm}^{-1}$ indicates a $\mathrm{C}-\mathrm{O}$ stretch anti-symmetrically coupled to the $\mathrm{C}-\mathrm{C}$ stretch, and the band at $649 \mathrm{~cm}^{-1}$ is the $\mathrm{O}-\mathrm{H}$ wag, all of these bands are characteristic of alcohols, carboxylic acids and free fatty acids, which were principally found in the traditional extraction.

The band located at $2920 \mathrm{~cm}^{-1}$ was assigned to $-\mathrm{CH}_{2}$ antisymmetric stretching; this band together with the band located at $1045-1074 \mathrm{~cm}^{-1}$ is characteristic of primary alcohols. The band located at $2855 \mathrm{~cm}^{-1}$ is the $-\mathrm{CH}_{3}$ symmetric stretch and bands between $1450 \mathrm{~cm}^{-1}$ and $1460 \mathrm{~cm}^{-1}$ represent the antisymmetric bend of the $\mathrm{CH}_{3}$ group. These bands are characteristic for MW, US and Soxhlet extractions.

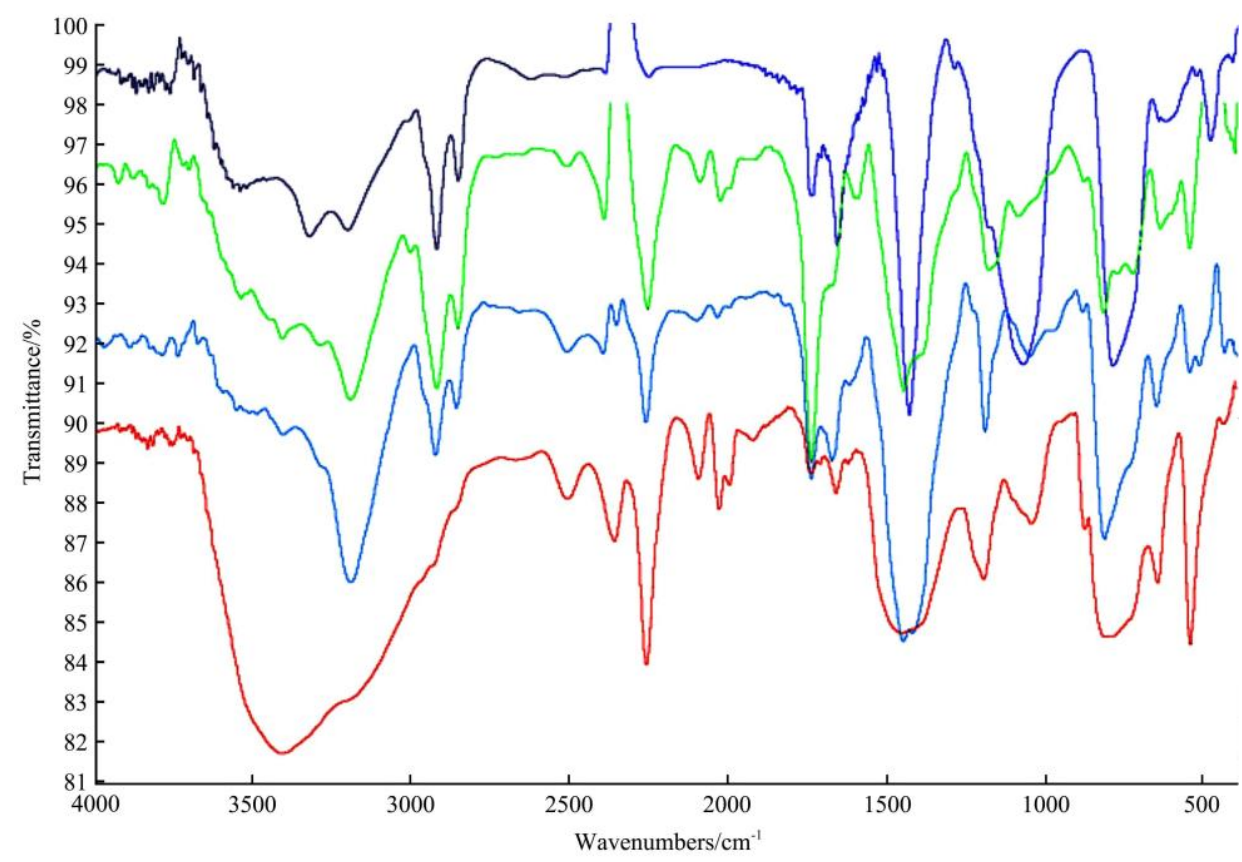

Figure 7 Fourier Transform Infrared spectrum: Ultrasonic (green line), Classical (orange line), Microwave (blue line), Soxhlet (black line)

Only in the US extraction, was a strong band found near $1735-1750 \mathrm{~cm}^{-1}$, which is characteristic of esters, representing the $\mathrm{C}=\mathrm{O}$ stretch in a saturated ester. Another important band between $3400 \mathrm{~cm}^{-1}$ and $3250 \mathrm{~cm}^{-1}$ in the US and Soxhlet extraction profile was the band at $3310 \mathrm{~cm}^{-1}$, which represents the N-H stretch of a secondary amine, and the strong band at $810 \mathrm{~cm}^{-1}$ is also due to the $\mathrm{N}-\mathrm{H}$ wag for a secondary amine. On the other hand, MW extraction shows two bands at $3335 \mathrm{~cm}^{-1}$ and $3190 \mathrm{~cm}^{-1}$ that, 
respectively, represent the antisymmetric $\mathrm{N}-\mathrm{H}$ stretch and symmetric N-H stretch in a primary amine. Additionally, the band at $1660 \mathrm{~cm}^{-1}$ indicates the $\mathrm{N}-\mathrm{H}$ bending vibration, and the strong band at $782 \mathrm{~cm}^{-1}$ is due to the $\mathrm{N}-\mathrm{H}$ wag of a primary amine. All of these bands are characteristic of lipids and related to the olefinic and nonolefinic fatty acids.

The major fatty acid composition of the tested microalgae was determined using GC analysis. The pattern of the FAMEs esters containing a fatty acid methyl carbon chain with a length between 8 and 24 carbon atoms was used.

The analysis showed that the MW and US extraction methods had a similar fatty acid composition. The same result was seen in the FTIR spectra. Palmitic acid was the most abundant fatty acid for these extraction methods, except for Soxhlet, in which it could not be extracted. The best method for extracting unsaturated fatty acids was MW, which extracted more oleic and linoleic acids compared to the other methods. Classical extraction yielded a similar amount of stearic acid as US, but stearic acid was low in the MW and Soxhlet extractions, and in the sample extracted by Soxhlet, only stearic acid was present (Table 3 ).

In all of the samples, the most representative acids were palmitic acid, which is used in the soap and cosmetics industries, and oleic and linoleic acids ( $\omega-6$ and $\omega-9)$, which have great importance in human health and are essential in the diet because they are not produced by the body. Saturated stearic acid is, also, of great importance in the cosmetics industry. The above results lead to the conclusion that GC-MS analysis was consistent with the FTIR results, and both techniques proved to be very useful for the analysis of lipids in microalgae.

Table 3 Relative amounts of fatty acids obtained with the different extraction methods

\begin{tabular}{lcccc}
\hline \multicolumn{1}{c}{ Fatty acid type } & $\begin{array}{c}\text { Classical } \\
\text { extraction }\end{array}$ & Microwave & Soxhlet & Ultrasound \\
\hline Palmitic acid (C16:0) & 30.62 & 44.25 & - & 52.58 \\
Palmitoleic acid $(\mathrm{C} 16: 1 \omega 7 \mathrm{c})$ & - & 0.51 & - & - \\
Linoleic acid $(\mathrm{C} 18: 2 \omega 6 \mathrm{c})$ & 18.89 & 26.99 & - & 15.41 \\
Oleic acid $(\mathrm{C} 18: 1 \omega 9 \mathrm{c})$ & 11.92 & 15.16 & - & 7.96 \\
$\gamma$-Linolenic acid & 5.00 & 6.61 & - & 4.33 \\
Stearic acid & 33.57 & 5.17 & 100.00 & 19.72 \\
10-octadecenoic acid & - & 1.30 & - & - \\
\hline
\end{tabular}

\section{Conclusions}

The optimal medium for the growth of A. obliquus was Bold $3 \mathrm{~N}$ modified medium because this medium allowed a higher biomass production. A greater number of living cells was produced during the exponential phase under $75 \%$ nitrogen; however, at the end of the experiment ( $15 \mathrm{~d})$, the number of cells was similar $(75 \%-100 \%$ of $\mathrm{N})$. The above results are in agreement with the lipid content established by the Red Nile method, which showed that the highest rate of lipid production occurred in the exponential phase, but similar to biomass, the lipid content was highest in the stationary phase.

All lipid extraction methods yielded similar amounts of lipids and the statistics of MW and US treatments are equal, however, MW extraction drastically reduced the extraction time compared to the other methods (1 min (MW) versus 35 min (US), $8 \mathrm{~h}$ (Soxhlet), and $24 \mathrm{~h}$ (classical) without affecting lipid production. The extraction time affected the profile of the fatty acids obtained. The unsaturated acids were extracted better by US and MW than by classical extraction. MW and US produced a similar fatty acid composition that only varied in the proportion of lipids obtained. Palmitic acid was obtained at the highest proportion with MW and US extraction as opposed to Soxhlet and classical extraction. On the other hand, stearic acid was extracted at high amounts by the classical and Soxhlet methods as opposed to MW and US extraction. Palmitic and stearic acid are very important for cosmetic industry. Oleic and Linoleic acids were produced by three methods, but MW extraction was the best method for the extraction of these lipids, which are very important in human health and diet because humans do not produce them.

\section{Acknowledgments}

The authors would like to thank at Universidad de La Sabana by the financing for the development of ING-140-2013 “Aplicación de técnicas de control proporcional integral generalizado al crecimiento de la microalga Scenedesmus obliquus" project. Additionally, they thank COLCIENCIAS for the "Doctorado Nacional-617-2" Scholarship given to C. L. Garzón-Castro. The authors would also like to thank at $\mathrm{PhD}$ Bioscience Program of the Universidad de La Sabana and at Universidad Nacional de Colombia.

\section{[References]}

[1] Posten C, Schaub G. Microalgae and terrestrial biomass as source for fuels-A process view. J Biotechnol, 2009; 142: 64-69. doi: 10.1016/j.jbiotec.2009.03.015.

[2] Brennan L, Owende P. Biofuels from microalgae-A review of technologies for production, processing, and extractions of biofuels and co-products. Renew Sustain Energy Rev, 2010; 14: 557-577. doi: 10.1016/j.rser.2009.10.009.

[3] Chisti Y. Biodiesel from microalgae beats bioethanol. Trends Biotechnol, 2008; 26: 126-131. doi: 10.1016/j.tibtech.2007.12.002.

[4] Bishop W M, Zubeck H M. Evaluation of microalgae for use as nutraceuticals and nutritional supplements. J Nutr Food Sci, 2012; 2. doi: 10.4172/2155-9600.1000147.

[5] Koller M, Muhr A, Braunegg G. Microalgae as versatile cellular factories for valued products. Algal Res, 2014; 6: 52-63. doi: 10.1016/j.algal.2014.09.002.

[6] Spolaore P, Joannis-Cassan C, Duran E, Isambert A. Commercial applications of microalgae. J Biosci Bioeng, 2006; 101: 87-96. doi: 10.1263/jbb.101.87.

[7] Beuckels A, Smolders E, Muylaert K. Nitrogen availability influences phosphorus removal in microalgae-based wastewater treatment. Water Res, 2015; 77: 98-106. doi: 10.1016/j.watres.2015.03.018.

[8] Suresh Kumar K, Dahms H U, Won E J, Lee J S, Shin K H. Microalgae A promising tool for heavy metal remediation. Ecotoxicol Environ Saf, 2015; 113: 329-352. doi: 10.1016/j.ecoenv.2014.12.019.

[9] Serive B, Kaas R, Bérard J B, Pasquet V, Picot L, Cadoret J P. Selection and optimisation of a method for efficient metabolites extraction from microalgae. Bioresour Technol, 2012; 124: 311-320. doi: 10.1016/j.biortech.2012.07.105.

[10] Parniakov O, Barba F J, Grimi N, Marchal L, Jubeau S, Lebovka N, et al. Pulsed electric field assisted extraction of nutritionally valuable compounds from microalgae Nannochloropsis spp. using the binary mixture of organic solvents and water. Innov Food Sci Emerg Technol, 2015; 27: 79-85. doi: 10.1016/j.ifset.2014.11.002.

[11] Viswanath B, Matanda T, White S, Bux F. The microalgae - A future source of biodiesel. Microalgae-A Futur Source Biodiesel Dyn Biochem Process Biotechnol Mol Biol, 2010.

[12] Escorsim A M, da Rocha G, Vargas J V C, Mariano A B, Ramos L P, Corazza M L, et al. Extraction of Acutodesmus obliquus lipids using a mixture of ethanol and hexane as solvent. Biomass and Bioenergy, 2018; 108: 470-478. doi: 10.1016/j.biombioe.2017.10.035.

[13] Remmers I M, Hidalgo-Ulloa A, Brandt B P, Evers W A C, Wijffels R H, Lamers P P. Continuous versus batch production of lipids in the microalgae Acutodesmus obliquus. Bioresour Technol, 2017; 244: 1384-1392. doi: 10.1016/j.biortech.2017.04.093. 
[14] The University of Texas at Austin. UTEX culture collection of algae at The University of Texas at Austin. UTEX 393, 2016. https://utex.org/products/utex-0393. Accessed on [2016-5-12].

[15] Li X, Hu H, Zhang Y. Growth and lipid accumulation properties of a freshwater microalga Scenedesmus sp. under different cultivation temperature. Bioresour Technol, 2011; 102: 3098-3102. doi: 10.1016/j.biortech.2010.10.055

[16] The University of Texas at Austin. UTEX the culture collection of algae, 2014. http://web.biosci.utexas.edu/utex/mediaDetail.aspx?mediaID=55. Accessed on [2016-05-12].

[17] Hodaifa G, Martínez M E, Sánchez S. Influence of $\mathrm{pH}$ on the culture of Scenedesmus obliquus in olive-mill wastewater. Biotechnol Bioprocess Eng, 2010; 14: 854-860. doi: 10.1007/s12257-009-0119-7.

[18] Shen X F, Liu J J, Chu F F, Lam P K S, Zeng R J. Enhancement of FAME productivity of Scenedesmus obliquus by combining nitrogen deficiency with sufficient phosphorus supply in heterotrophic cultivation. Appl Energy, 2015; 158: 348-354. doi: 10.1016/j.apenergy.2015.08.057.

[19] Cooksey K E, Guckert J B, Williams S A, Callis P R. Fluorometric determination of the neutral lipid content of microalgal cells using Nile Red. J Microbiol Methods, 1987; 6(6): 333-345. doi: 10.1016/01677012(87)90019-4.

[20] Isleten-Hosoglu M, Gultepe I, Elibol M. Optimization of carbon and nitrogen sources for biomass and lipid production by Chlorella saccharophila under heterotrophic conditions and development of Nile red fluorescence based method for quantification of its neutral lipid content.
Biochem Eng J, 2012; 61(4): 11-19. doi: 10.1016/j.bej.2011.12.001.

[21] Gao S, Takemura S, Ting CY, Huang S, Lu Z, Luan H, et al. The Neural Substrate of Spectral Preference in Drosophila. Neuron, 2008; 60(2): 328-342. doi: 10.1016/j.neuron.2008.08.010.

[22] Rumin J, Bonnefond H, Saint-Jean B, Rouxel C, Sciandra A, Bernard O, et al. The use of fluorescent Nile red and BODIPY for lipid measurement in microalgae. Biotechnol Biofuels, 2015; 8(1): 42. doi: 10.1186/s13068-015-0220-4

[23] Ott R L, Longnecker M. Statistical methods and data analysis. Seventh Boston, 2016.

[24] Balasubramanian S, Allen J D, Kanitkar A, Boldor D. Oil extraction from Scenedesmus obliquus using a continuous microwave system--design, optimization, and quality characterization. Bioresour Technol, 2011; 102 3396-3403. doi: 10.1016/j.biortech.2010.09.119.

[25] Florentino de Souza Silva A P, Costa M C, Colzi Lopes A, Fares Abdala Neto E, Carrhá Leitão R, Mota C R, et al. Comparison of pretreatment methods for total lipids extraction from mixed microalgae. Renew Energy, 2014; 63: 762-766. doi: 10.1016/j.renene.2013.10.038.

[26] Prabakaran P, Ravindran A D. A comparative study on effective cell disruption methods for lipid extraction from microalgae. Lett Appl Microbiol, 2011; 53: 150-154. doi: 10.1111/j.1472-765X.2011.03082.x.

[27] Koberg M, Cohen M, Ben-Amotz A, Gedanken A. Bio-diesel production directly from the microalgae biomass of Nannochloropsis by microwave and ultrasound radiation. Bioresour Technol, 2011; 102(5): 4265-4269. doi: 10.1016/j.biortech.2010.12.004. 